year 5. (Salman R A-S et al. Lancet Neurol March 2012;11:217-224). The increased risk in women in this study of adults only is different from that in the Mayo Clinic study showing a preponderant risk in males.

\title{
SECKEL SYNDROME WITH HOLOPROSENCEPHALY
}

A case of Seckel syndrome (SS) accompanied by semilobar holoprosencephaly and arthrogryposis is reported from Erciyes University, Kayseri, Turkey. Seckel syndrome is a rare autosomal recessive disorder characterized by prenatal and postnatal growth retardation, microcephaly, and "bird-like" face with prominent, beak-like nose and micrognathia. A 1-day-old female newborn was admitted with dysmorphic features and feeding difficulties. The parents were consanguineous. In addition to typical features of SS, the baby had arthrogryposis, and cranial MRI showed semilobar holoprosencephaly, lissencephaly/pachygyria, dilated occipital horn of the lateral ventricle, hypoplasia of the frontal horn, non-cleavage of the basal ganglia and frontal lobe, and dysgenesis of the corpus callosum. Neuronal migration disorders should be investigated in infants born with facial characteristics of SS. (Sarici DS, Akin MA, Kara A, Duganay S, Kurtoglu S. Seckel syndrome accompanied by semilobar holoprosencephaly. Pediatr Neurol March 2012;46:189-191). (Respond: Dr Sarici. Email: drdilekcoban@yahoo.com.tr).

COMMENT. Holoprosencephaly (HP) is presented as a new associated feature of SS. Based on grades of severity, this case is a semilobar form of HP. The mechanism of the facial dysmorphism in SS may be attributable to defective mesencephalic neural crest tissue formation (Sarnat HB, Flores-Sarnat L. J Child Neurol 2001;16;918-931).

\section{LEARNING DISABILITIES}

\section{TRACTOGRAPHY NEUROANATOMICAL STUDY OF DYSLEXIA}

Researchers at Catholic University of Leuven, Belgium used diffusion tensor imaging tractography, a structural MRI technique, to assess the integrity of white matter tracts involved in reading. Group comparisons of 20 adults with dyslexia and 20 typical reading adults showed a significantly reduced fractional anisotropy (i.e. an index of the amount of anisotropy) in the left arcuate fasciculus of dyslexics, reflecting reduced myelination. Performance on phoneme awareness and speech perception was specifically related to the integrity of the left arcuate fasciculus (dorsal phonological route underlying grapheme-phoneme decoding), whereas orthographic (direct word) processing was related to fractional anisotropy values in the left inferior fronto-occipital fasciculus (ventral orthographic route). Structural anomalies found in the left arcuate fasciculus of dyslexics corroborate the hypothesis of dyslexia as a disorder of network connections. (Vandermosten M et al. Brain 2012;135:935-948).(Response: M Vandermosten. E-mail: maaike.vandermosten@ppw.kuleuven.be).

COMMENT. Dyslexics have reduced white matter integrity in the component of the left arcuate fasciculus that links Wernicke's to Broca's area. 